\title{
Contents Volume 3
}

No. 1

Mercury from dental amalgams: exposure and effects

J. Pleva (Sweden)

Medical responsibility in Greece: analysis of a case of medical negligence P. Dalla-Vorgia and T.N. Garanis (Greece)

False positive diagnosis of arterial hypertension: the diagnostic errors and their avoidance

H. Van Viet, P. Chevalier, C. De Jaeger and R. Rullière (France)

The funding of quality in medicine: one country's challenge W.J. Keon (Canada)

Retained needle in surgery

Health Action International: networking for rational drug use C. Hodgkin (The Netherlands)

Collaborative Group on Drug Use in Pregnancy (CGDUP) 49

Hippocrates $\quad 53$

Forthcoming Meetings $\quad 58$

Information for Authors $\quad 59$

No. 2

Needles, AIDS, and lessons unheeded?

Malpractice: new under the sun? P. Barington (Canada)

Ethical issues in the relationship between American physicians and drug companies M.B. Kapp (U.S.A.)

The Danish Patient Insurance Act of 1991 (LOV 1991-06-06 NR 367 OM PATIENTFORSIKRING)

N. Fenger and M. Broberg (Denmark)

Ovulation-inducing drugs: a drug utilization and risk study in the Dutch population L.T.W. De Jong-van den Berg, M.C. Cornel, P.B. Van den Berg, A.C.A. Bortolussi, H.M. Twerda, R.E. Lappöhn and H. Wesseling (Netherlands) 
Forthcoming Meetings 113

Health devices: a correction and a postscript 114

Book Review $\quad 115$

Announcement from the Publisher $\quad 116$

$\begin{array}{ll}\text { Information for Authors } & 117\end{array}$

No. 3

Malpractice: civil, criminal and disciplinary cases

Monitoring of risk factor/outcome combinations: a valuable supplement to birth defect monitoring

L.P. Ten Kate, M.C. Cornel and H.E.K. De Walle (Netherlands)

The rights of patients versus the obligations to sponsors in clinical trials K.H. Kimbel (Germany)

Silicone breast implants: the situation in 1991 M.N.G. Dukes (The Netherlands)

Chewing khat, an old drug habit that is new in Europe P. Kalix (Switzerland)

Canadian Medical Association: Fourth Annual Leadership Conference, Ottawa, ON, Canada, February 1992

J. David (Canada)

Routine control of oral contraceptive users: a new 'standard' in The Netherlands

C. Van Weel (The Netherlands)

American Government scientists: availability as expert witnesses in private litigation concerning pharmaceutical product injuries W.J. Curran (USA)

Reviews of books and studies 167

Forthcoming Meetings $\quad 171$

Hippocrates 173

Information for Authors $\quad 177$

No. 4

Editorial

Spontaneous reporting of fatal adverse drug reactions S.H.L. Thomas and M.D. Rawlins (UK) 


\section{Regular Papers}

Hormone therapy during pregnancy and isolated hypospadias: an international case-control study

B.A.J. Källén, M.L. Martínez-Frías, E.E. Castilla, E. Robert, P.A.L. Lancaster, M. Kringelbach, O.M. Mutchinick and P. Mastroiacovo (Sweden, Spain, Brazil, France, Australia, Denmark, Mexico, Italy)

The composition of drinking water and the prevalence of anencephalus and spina bifida in New Zealand

B. Borman and C. Cryer (New Zealand, UK)

First-trimester in utero exposure to anorectics: a French collaborative study with special reference to dexfenfluramine

T. Vial, E. Robert, P. Carlier, E. Bertolotti and A. Brun (France)

The duty to report hospital occurrences resulting in injuries and risks of injury: The Norwegian system

O. Molven (Norway)

Case Commentary

The DES product liability story in America: The third generation litigation W.J. Curran (USA)

Book Review

Extraokulare Nebenwirkungen lokal applizierter Ophthalmika reviewed by B.C.P. Polak

Forthcoming Meetings

Information for Authors

No. 5,6

Editorial

Witness in America

M.N.G. Dukes

\section{Regular Papers}

Infection control and risk assessment: a review, a pilot survey and recommendations

D.R. Morgan (UK)

Medical accidents: attitudes and opinions of doctors

K. Gannon (UK)

Informed consent in medicine: one physician's perspective R.J. Klingenstein (USA) 
Caesarean section in obstetric practice of a developing southern Mediterranean island

C. Savona-Ventura (Malta)

Medical and peer review records in malpractice litigation

D. Florin and J.G. Murphy (USA)

Profile

The International Foundation for Drug Efficacy and Safety

Forthcoming Meetings

Review

Malpractice: civil, criminal and disciplinary cases

\section{Reports}

Principles of risk analysis

How to cope with different medical cultures in Europe R. Randling (UK)

A case of fluoxetine-induced stimulant side effects with suicidal ideation associated with a possible withdrawal reaction ("crashing")

P.R. Breggin (USA)

Hippocrates

Book Reviews

Power and dependence; social audit on the safety of medicines 337

Patient compliance in medical practice and clinical trials 338

$\begin{array}{ll}\text { Follies and fallacies in medicine } & 340\end{array}$

Idiosyncratic reactions to valproate. Clinical risk patterns and mechanisms of toxicity

Contents Volume 3

Cumulative Index 1990-1992

347

Information for Authors

Contents continued from back cover 